\title{
"It's better to have three brains working instead of one": a qualitative study of building therapeutic alliance with family members of critically ill patients
}

Csilla Kalocsai ${ }^{1,5^{*}}$ (D), Andre Amaral ${ }^{1,2,3}$, Dominique Piquette ${ }^{1,2,3}$, Grace Walter ${ }^{3}$, Shelly P. Dev ${ }^{2,3}$, Paul Taylor ${ }^{3}$, James Downar ${ }^{2,4}$ and Lesley Gotlib Conn ${ }^{1}$

\begin{abstract}
Background: Studies in the intensive care unit (ICU) suggest that better communication between families of critically ill patients and healthcare providers is needed; however, most randomized trials targeting interventions to improve communication have failed to achieve family-centered outcomes. We aim to offer a novel analysis of the complexities involved in building positive family-provider relationships in the ICU through the consideration of not only communication but other important aspects of family-provider interactions, including family integration, collaboration, and empowerment. Our goal is to explore family members' perspectives on the enablers and challenges to establishing therapeutic alliance with ICU physicians and nurses.
\end{abstract}

Methods: We used the concept of therapeutic alliance as an organizational and analytic tool to conduct an interviewbased qualitative study in a 20-bed adult medical-surgical ICU in an academic hospital in Toronto, Canada. Nineteen family members of critically ill patients who acted as substitute decision-makers and/or regularly interacted with ICU providers were interviewed. Participants were sampled purposefully to ensure maximum variation along predetermined criteria. A hybrid inductive-deductive approach to analysis was used.

Results: Participating family members highlighted the complementary roles and practices of ICU nurses and physicians in building therapeutic alliance. They reported how both provider groups had profession specific and shared contributions to foster family communication, integration, and collaboration, while physicians played a key role in family empowerment. Families' lack of familiarity with ICU personnel and processes, physicians' sporadic availability and use of medical jargon during rounds, however, reinforced long established power differences between lay families and expert physicians and challenged family integration. Family members also identified informal interactions as missed opportunities for relationship-building with physicians. While informal interactions with nurses at the bedside facilitated therapeutic alliance, inconsistent and ad-hoc interactions related to routine decision-making hindered family empowerment.

Conclusions: Multiple opportunities exist to improve family-provider relationships in the ICU.

The four dimensions of therapeutic alliance prove analytically useful to highlight those aspects that work well and need improvement, such as in the areas of family integration and empowerment.

Keywords: Therapeutic alliance, Communication, Collaboration, Decision-making, shared, Family, Intensive care units, Qualitative research

\footnotetext{
*Correspondence: csilla.kalocsai@camh.ca

${ }^{1}$ Trauma, Emergency and Critical Care Research, Evaluative Clinical Sciences,

Sunnybrook Research Institute, Toronto, Canada

${ }^{5}$ Patient/Client and Family Education, Centre for Mental Health and

Addiction, 33 Russell Street, Toronto, Ontario M5S 3M1, Canada

Full list of author information is available at the end of the article
}

(c) The Author(s). 2018 Open Access This article is distributed under the terms of the Creative Commons Attribution 4.0 International License (http://creativecommons.org/licenses/by/4.0/), which permits unrestricted use, distribution, and reproduction in any medium, provided you give appropriate credit to the original author(s) and the source, provide a link to the Creative Commons license, and indicate if changes were made. The Creative Commons Public Domain Dedication waiver (http://creativecommons.org/publicdomain/zero/1.0/) applies to the data made available in this article, unless otherwise stated. 


\section{Background}

Family members of critically ill patients value high-quality communication with the health care team [1]. Where family-provider communication has been suboptimal, patient-, family-, and staff-centered outcomes have suffered [1-8]. Patient safety and quality of care, family satisfaction and mental health, and staff wellness are affected [1-13]. Increasing healthcare costs are also associated with poor family-provider communication. These studies suggest that better communication between families and healthcare providers is needed in the intensive care unit (ICU) [3-8], yet most randomized trials targeting interventions to improve communication have failed or paradoxically led to worsening symptoms in family-centered outcomes [14-18]. This may be due to the limited focus of these interventions on communication regarding end-of-life care during formal, scheduled family meetings. While end-of-life care is an extremely important issue, family-provider interaction frequently begins well before end-of-life conversations are held or needed. In contrast, other fundamental dimensions of family-provider interactions, such as family daily involvement in care [10, 17-22], trust and support [1, 21-23], and family empowerment $[1,10,19,23,24]$, receive relatively little scholarly attention.

By considering the multidimensionality and evolving nature of family-provider interactions, this study offers an examination of the complexities through which positive family-provider relationships may be established. We have drawn upon the concept of therapeutic alliance, which focuses on interrelated and essential dimensions of relationship-building between ICU families and providers: communication, integration, collaboration, and empowerment [25-27]. Therapeutic alliance is an ideal relationship that emerges between patients (or families as surrogates) and providers when conditions of these four distinct dimensions are met: a) effective information exchange and empathetic communication; b) integration of families into the care team through equalization of power by providers; c) collaboration between families and providers in establishing mutually agreed goals; and d) empowerment of families by providers to partner in decision-making [25-27]. While it is analytically useful to distinguish among these four dimensions for a holistic and complex inquiry into family-provider interactions and relationship-building, these dimensions are interrelated, as illustrated by their names and definitions. For example, integration and empowerment intersect partially, as integration is defined by the equalization of power between families and providers, and empowerment is the partnering in decision-making, that is, a particular type of integration. Therefore, integration can be established through empowerment, just as collaboration develops through communication.
Therapeutic alliance is associated with better outcomes [28-30]. Strong therapeutic alliance is related to emotional acceptance of terminal illness and less aggressive ICU care among patients with advanced cancer [29]. A recent study of family members of critically ill patients observed that therapeutic alliance was associated with families' perception of increased patient-centered care [31]. However, the question of how positive relationships are actually built, or what behaviors, attitudes and practices contribute to therapeutic alliance in the ICU remains unexamined. In order to develop an in-depth understanding of the dynamic and evolving social relationships between families and providers during an ICU stay, we have taken a qualitative approach. This study explores family members' perspectives on the enablers and challenges to positive relationship-building with ICU physicians and nurses with a view to further understand and optimally support patient- and family-centered outcomes.

\section{Methods \\ Study design and setting}

We conducted a qualitative study, using semi-structured interviews to explore families' experiences and perspectives of how positive relationships are built with critical care providers. We followed a constructivist paradigm and focused our inquiry on the lived experience and the various ways in which families understand or make sense of their experiences of provider-family relationships [32].

The study took place in a 20-bed adult medical-surgical ICU of an academic hospital in Toronto. Sixteen staff physicians work on a weekly rotation schedule, with two covering physicians dividing patient care responsibilities in the unit of study. The two covering staff physicians also service other ICUs located in other parts of the hospital, and thus each cares for between 14 and 20 patients per physician at any given time. Clinical fellows (physicians certified in a base specialty who do further training in critical care) and residents (medical trainees enrolled in various specialty programs, including surgery, anaesthesia, emergency and general medicine) also participate in the care of ICU patients with variable assignment length to given patients (e.g.: for a day, a night, a week). One fellow and two residents are responsible for nighttime coverage. The ICU is staffed with nurses working 12-h shifts, with a 1:1 nurse to patient ratio. Other healthcare providers in the ICU include social workers, consultant physicians, pharmacists, dietitians, physiotherapists, respiratory therapists, speech-language pathologists and spiritual care providers. The study focuses on families' interactions with physicians and nurses, because we only received limited data on other providers. 


\section{Participants and sampling}

We used a purposive sampling strategy with criterion and maximum variation sampling techniques [33]. English-speaking family members of ICU patients undergoing prolonged ventilation with a minimum stay of $48 \mathrm{~h}$ and a maximum stay of 1 month were eligible. We recruited family members of a diverse patient population and belonging to a wide range of demographics. We interviewed families who were present during daytime hours as well as those who were not available during daytime or did not visit regularly.

\section{Data collection and analysis}

Interviews were conducted in-person in the family meeting room of the ICU. The interview guide was based on research team expertise and a literature review on therapeutic alliance, communication and conflict in the ICU (Additional file 1). A cultural anthropologist with prior experience in health services research (CK) interviewed all participants. The interviews lasted for 30 to $80 \mathrm{~min}$, were audio-recorded and transcribed verbatim. Originally, we planned to include only substitute decision makers (SDM), who are legally required to make decisions and to give consent on behalf of their incapacitated relatives, but found that in some instances other family members interacted with providers more frequently, and thus those relatives were also included in the study.

The analysis was iterative and followed a hybrid inductive-deductive approach [34]. Three investigators (CK, LGC, DP) read and coded the first six transcripts independently to determine major themes and identify areas for additional inquiry. Through discussions with the research team, the primary author (CK) analyzed the remaining transcripts to refine and expand the coding scheme using the constant comparison method. Data collection ceased when saturation was reached [33]. Following an initial inductive coding strategy and to guide further interpretation, we used the four dimensions of the therapeutic alliance concept as an organizational and analytic tool. NVivo 10 was used for data storage and management.

\section{Results}

We interviewed 19 family members, 17 SDMs and 2 non-SDMs between October 2014 and February 2015 (Tables 1 and 2). Nurses' and physicians' complementary roles and practices fostered therapeutic alliance across $3 \mathrm{di}-$ mensions: communication, integration, and collaboration. Family members perceived that only physicians were positioned to empower them to participate in decision-making. Study participants also revealed barriers and missed opportunities to establishing therapeutic alliance, especially in the integration and empowerment dimensions. Therapeutic alliance was challenged by certain physician practices that unintentionally perpetuated power differences with families,
Table 1 Characteristics of family participants $(n=19)$

\begin{tabular}{ll}
\hline Characteristics & Value \\
\hline Female, n (\%) & $14(74 \%)$ \\
Age, mean (range) & $47(20-72)$ \\
Race/Ethnicity & \\
White, n (\%) & $13(68 \%)$ \\
Black, n (\%) & $2(10 \%)$ \\
Other, n (\%) & $4(21 \%)$ \\
Religion & \\
Christian, n (\%) & $13(68 \%)$ \\
Other, n (\%) & $4(21 \%)$ \\
Non-religious, n & $2(10 \%)$ \\
Substitute Decision Maker, n (\%) & $17(89 \%)$ \\
Relationship to Patient & \\
Spouse, n (\%) & \\
Child, n (\%) & $5(26 \%)$ \\
Parent, n (\%) & $9(47 \%)$ \\
Other, n (\%) & $4(21 \%)$ \\
Dafter hours and non-regular visitation, n (\%) & $1(5 \%)$ \\
\hline
\end{tabular}

alienating them and hindering family integration. Missed opportunities for informal interactions between physicians and family members further challenged family integration and empowerment and thus the establishment of positive family-provider relationships. These findings are elaborated below.

\section{Communication: Exchanging information and providing empathy}

Through distinct and shared communication practices nurses and physicians built positive relationships with

Table 2 Characteristics of patients $(n=19)$

\begin{tabular}{ll}
\hline Characteristics & Value \\
\hline Female, n (\%) & $9(47 \%)$ \\
Age, mean (range) & $54(17-87)$ \\
Reasons for admission, $n(\%)$ & \\
Neuro and TBI & $8(42 \%)$ \\
Respiratory & $4(21 \%)$ \\
Sepsis & $2(10-\%)$ \\
Postoperative elective & $1(5 \%)$ \\
Trauma & $4(21 \%)$ \\
Length of Stay at Time of Interview & \\
2 to 4 days & $2(10 \%)$ \\
5 to 10 days & $8(42 \%)$ \\
More than 11 days & $9(47 \%)$ \\
\hline
\end{tabular}


family members. Physicians provided medical information, while nurses facilitated the understanding of medical updates and provided sustained emotional support with frequent, reliable, clear, and empathetic communication throughout the day.

Family members recognized both nurses and physicians as valuable sources of information regarding the patient's condition and care:

"Many people like to be informed, they like to know what's going on so they don't feel lost and helpless."

Beyond content, communication style and delivery mattered tremendously to families and, when done with clarity and empathy, communication positively contributed to building relationships. Participants appreciated "honest" and sincere information during bedside updates or family meetings, and sometimes used the term "no sugar-coating" to describe effective communication with both nurses and physicians.

Proactively sharing and frequently repeating information helped families. "Forthcoming" providers were valued by families who were concerned with asking too many questions, and by those who struggled to ask any questions: "How do you know what questions to ask the doctor?" Families felt reassured by repetitive information provided by nurses and physicians, highlighting the importance of their complementary practices:

\section{"I find the doctor corroborates what the nurse said. It is nice to hear it again."}

Family members perceived nurses to be especially good at explaining clinical information in simple, jargon-free language. As they put it, nurses talked "in our language." Nurses were perceived as a reliable source of answers to questions emerging among family members during informal updates, and bedside rounds.

Families recognized physicians' compassionate communication during family meetings focused on end-of-life issues, but viewed nurses as expressing empathy more consistently throughout the patients' ICU stay. They not only appreciated how nurses respectfully treated unconscious patients, but how they addressed family distress: "They can even comfort me and help me get through this." Nurses built emotional connections with family members through concrete gestures, such as asking how they were doing, bringing an extra chair, or offering a bottle of water. As one family member put it:

"I don't know if anyone realizes just how important that personal touch is. Nurses are there to do the job and they do it well, but they also give you a hug and a smile. And reassurance - they aren't miracle workers but you'd almost think that they were."

\section{Integration: Equalizing power differences}

Although some positive aspects of communication were recognized by our participants in both nurses and doctors, others were seen as specific to one professional group. Physicians were uniquely recognized for integrating families into the care team by encouraging them to attend daily interdisciplinary rounds and to participate in the exchange of information and decision-making regarding patient care. Rounds were recognized as the most reliable opportunity to speak with physicians, and many family members scheduled their ICU visits in order to attend this morning activity. Some of these families reported that staff's questions made them feel valued: "They know that I know my mom best." Others appreciated receiving a brief update about their loved one at the end of the team's discussion. Some families found that attending rounds helped to "build trust and community."

However, family members who gained access to interdisciplinary rounds did not necessarily feel integral to patient care. Integration was challenging for some families because of the technical discussion occurring during rounds. Many families reported that "most of what I hear I don't understand." Inaccessible language typically used by interdisciplinary team members made rounds "overwhelming" and "intimidating" for family members.

While physicians were mostly available during daily rounds and formal family meetings, family members found nurses to be more continuously available at the bedside. They appreciated having the same nurse for a few consecutive days: "It's nice to have the face that I know and can talk to easily." They often knew the nurses by name, and with prolonged patient ICU stay, families "really got to know" them. Families acknowledged that nurses' availability was limited due to scheduling, but valued how nurses integrated them by recognition and reconnection, as they came back to the bedside to give them a hug, or chatted with them while taking care of a patient nearby. Nurses facilitated family members' integration by acting as an intermediary between the family and other members of the health care team. They sought out answers to family questions, and involved families in direct patient care delivery, for example, putting lotion on their loved one's hands, wetting their lips, and accompanying their loved one on the way to the operating room.

By contrast, physicians' sporadic presence at the bedside or in the unit was perceived to hinder family integration into the team. Many families found, for example, "It's a hit and miss if you see a doctor." Some families 
complained that staff physicians did not always come back to update them after rounds as promised. Those who visited exclusively during evenings or weekends reported never communicating with the physician in charge:

"We found out who was responsible, but never had the opportunity to meet him in person. It was always residents."

Scheduling practices and the teaching orientation of the clinical environment were some of the structural factors that shaped and constrained physicians' work: staff physicians rotated weekly, handovers occurred twice daily between daytime and nighttime clinical teams, and multiple providers were involved in the daily care of each patient. This large and often changing team of physicians confused families:

"I feel like so many different people are with her all the time. It's not like one main person. So I get confused half of the time."

A family member thus compared her experience with the care team to "a revolving door." Many participants admitted to not knowing who the physician in charge was, or identified the wrong individual:

"I still don't know which doctor is in charge of him. I just know [Dr. XY] did the surgery. But I think it's his students who are actually doing the rounds but I don't know if there is actually one student in charge of him."

It was also common for family members to mistake medical trainees for nurses. A family member summed up the problem of staff identification as follows: "I wouldn't know who is a doctor, everyone who has a stethoscope?" This structure added to families' confusion, and was enhanced by doctors frequently failing to introduce themselves to the family at the bedside: "It would be nice just to say hi, I'm so-and-so."

Yet, families assumed their share of responsibility for the shortcomings in physician-family interactions by recognizing their own passivity in requesting updates and pointing to their own limited availability. They also believed that physicians' limited presence was at times justifiable because of their busy schedules and competing priorities: "They would rather spend the time taking care of the patients than telling me what's going on."

Access to providers and to the patient was therefore an essential, and sometimes limiting, factor in family integration in patient care, but was not in itself sufficient to family integration. The understanding of ICU roles and rules, norms and practices, language and structures, however, proved essential to full family integration but often remained incomplete.

\section{Collaboration: Establishing mutually agreed goals}

Family members reported that advocating and proactively working with nurses and physicians enhanced their feeling of collaboration with the ICU team: "It's better to have three brains working instead of one." Families positively reflected on formal, scheduled family meetings with physicians aimed at reassessing goals of care. They highlighted how doctors "made the time to speak" with them, discussed patient values and hopes, and brought the bad news "apologetically." Physicians were perceived as helpful for answering questions and advising on decision-making related to life-supporting therapies. In doing so, physicians often expressed uncertainty and empathy.

As families advocated for their loved ones, they valued how nurses listened to their simple suggestions, such as which side their loved one liked to lie on. They also appreciated sharing personal knowledge of the patient, for example, the existence of allergies, need for pain medication, or discomfort caused by procedures. Families liked when nurses seriously considered what they suggested: "So they would really not dismiss any of my comments, they would say, okay let's see together and get things sorted out."

Addressing family members' knowledge of the patient was found imperative to establish daily and bigger picture goals. While physicians collaborated with families to establish complex, overarching care goals, nurses collaborated with family members to reach everyday goals.

\section{Empowerment: Partnering in decision-making}

Physicians played a key role in empowering families in sharing decision-making during formal and scheduled family meetings about a wide range of medical decisions, from tracheostomy to blood transfusion and surgery. Family members described how clear and understandable explanations about the care plan helped them make decisions: "He laid it out very well so that we could make more of an informed decision now." Families also appreciated when physicians respected their decisions even if they disagreed with the plan: "They did not write up the order, which I think is really positive because they could tell by my reaction that I wasn't comfortable with it."

Formal, scheduled meetings and end-of-life discussions were therefore described positively, but informal bedside or phone interactions with physicians appeared less satisfactory for families, representing a missed opportunity for family empowerment. A number of families described inconsistencies in how physicians sought their input to make smaller-scale decisions related to the 
daily care of patient. One participant complained that a physician called her to consent for a blood transfusion, though on previous occasions the patient received the same treatment without her consent. Another participant perceived that clinicians preferentially engaged them when physically present at the bedside, "because they were already in the room and wanted to do the procedure." Similarly, another participant found it upsetting to be called while traveling by bus to the hospital in order to make a hasty decision about a non-urgent procedure that later proved unnecessary:

"They thought he was bleeding in his stomach so they wanted to put a tube down his throat to see about that. It was kind of bad timing. I was on the bus and I really couldn't hear. The conversation probably went well but I was caught off-guard. ... I should have said, I'm on my way, I'll be there in a minute and can we hold off 5 min because I would like to ask a question first before you do this?"

These inconsistent ways of seeking family input for decision-making during informal family-physician interactions left families questioning how truly valued their contribution to decision-making was, and thus challenged family empowerment. They created confusion about their role as SDMs, leading them to decisional regret, loss of trust, and the feeling of exclusion from the care team.

\section{Discussion}

Family members experience many facilitators and barriers to building therapeutic alliance in the ICU. We found this to be a complex and dynamic process, evolving through a series of formal and informal social interactions between families and different healthcare providers. We observed three findings: First, nurses and physicians occupy complementary roles and perform complementary practices through which they together foster positive relationships with family members. Family members described their complementary practices in communication, integration, and collaboration, and highlighted physicians' role in empowering them in decision-making. Second, families' lack of familiarity with ICU personnel and processes, physicians' limited availability and use of medical jargon during rounds often reinforced long established power differences between lay families and expert physicians, and thus challenged family integration and the establishment of therapeutic alliance. Third, families highlighted informal interactions as missed opportunities for physicians to build therapeutic alliance. While informal conversations and interactions with nurses at the bedside facilitated positive relationships, inconsistent and ad-hoc communication about decision-making led to a sense of family confusion, which challenged family empowerment and alienated them from the care team.

Our analysis shows that therapeutic alliance in the ICU is an interprofessional effort that relies on doctors and nurses in different ways. While the importance of interprofessional communication in this dyad is known, these findings uniquely highlight how families perceive and experience the profession specific and interprofessional strategies to communication, integration, collaboration, and empowerment. For example, repetition, corroboration and clarification are interprofessional communication strategies reflecting physicians' and nurses' collaboration in establishing therapeutic alliance with families. As a result, family members are reassured, supported, and kept informed. Previous research, however, has identified the need for an interprofessional strategy to improve family communication and decision-making [15, 35-38], with an emphasis on third-party facilitation $[14,15,17,18]$. Our findings suggest that nurses and physicians are well positioned to share responsibility for fostering positive relationships with families, which could benefit both families and providers. Identifying the specific contributions that each profession brings to this relationship and effectively leveraging them appears as an important strategy to improve family-centered outcomes. Acknowledging one another's contributions towards this shared goal could also provide a mechanism through which some of the interdisciplinary tensions between nurses and physicians, due to differences in professional cultures, medical dominance, and competing interests, can be mitigated in the ICU [39-43].

Nurses' and physicians' interactions with families, and their complementary roles and practices in building therapeutic alliance with them are heavily determined by structural factors, such as provider coverage models and the teaching orientation in the particular ICU. Such factors shape physician-family interaction as more sporadic, which can still achieve important benefits in the moment along the dimensions of communication, integration, collaboration and empowerment. In contrast, nurse-family interaction can become more longitudinal and consistent, conducive for empathetic communication and the establishment of an emotional bond. Although the inclusion of nurses in decision-making about goals of care is recommended by current guidelines, this recommendation is based on studies that employed a non-bedside, usually specially trained nurse [1]. Our findings, however, suggest that further research should explore and tap into the potential of bedside nurses in supporting families and achieving therapeutic alliance.

Findings related to integration offer insights into power relations operating between ICU providers and families. 
Inequalities have been previously explored across various clinical contexts $[44,45]$, but our findings bring attention to the complexity of power relations with families in the ICU. Daily rounds provide opportunities for family participation and integration into the team, and may reduce the historically established power differences between expert doctors and lay family. Some families, however, experienced discomfort and a sense of exclusion due to physicians' use of technical language, revealing how family attendance on rounds does not necessarily lead to family-centered rounds [46, 47]. These bedside rounds were intended primarily to make decisions about patient care and teach medical trainees, but recently, along with the movement towards person-centered care, they were opened up for the inclusion of families. By observing how power differences are perpetuated through language [48], our study demonstrates and explains the challenge of family inclusion in daily rounds and the potential for unintended consequences. It thus expands on other studies that point to the increase in family anxiety during rounds without unpacking its source [1]. To achieve family integration through rounds, we echo the Society of Critical Care Medicine's (SCCM) call for further research on the best ways to incorporate families into rounds beyond their mere presence [1].

Family members' tendency to rationalize physicians' limited presence by their busy schedules and competing priorities also reinforces hierarchical relations in family-provider interactions. Notwithstanding physicians' intensive workflow, it is important to highlight how families' justifications quickly subscribe to the culturally dominant narrative of physicians' being too busy to spend time talking with them. Recognizing time as a differential resource, families lower their expectations about possible physician-family encounters and take up a more passive role. They unintentionally eclipse communication as physicians' professional responsibility and curtail opportunities for their integration into the team. Such assumptions and associated behaviors point to the dynamics of physician-family interaction and how family members are complicit in the reproduction of power relations, posing a barrier to establishing positive relationships. The concept of therapeutic alliance overlaps with other important contemporary goals of health care, such as family-centered care and shared decision-making, all of which value egalitarian relations [45], but our analysis finds that they often remain ideals in a cultural context mediated by power.

Therapeutic alliance also provides a useful lens to understand the importance of informal encounters in shaping relationships in the ICU [20, 22, 49]. Families highlighted the value of nurses' informal and consistent updates and other interactions, through which nurses effectively communicated and collaborated with families, and integrated them into the care team. In contrast, physicians' sporadic presence and episodic communication patterns at formal, scheduled meetings constrained the relationships they built with families. Furthermore, inconsistencies in physicians' informal interactions around consenting procedures often challenged family empowerment, impeding therapeutic alliance and possibly contributing to conflict. Although studies and guidelines to date have mostly focused on formal interactions, such as family meetings about end-of-life and other big decisions [1, 16, 17, 23, 50, 51], our findings call for the recognition that informal, ad hoc interactions with a range of providers over time are important part for establishing therapeutic alliance. Further research on how informal interactions influence the family-provider relationship is needed.

This study is novel in its qualitative approach to therapeutic alliance. It has used a broad sampling strategy to include family members of a diverse patient population in order to draw out commonalities in their experiences during the patient's ICU stay. Further research is needed to understand how ICU providers build relationship with specific family groups, in particular those who are not English-speaking or those whose loved one belongs to medical versus surgical populations. The study is also unique in its focus on families' interactions with nurses and physicians simultaneously, at the exclusion of participants' experiences with other health care team members. Future work should explore family-provider interactions from both the families' and all health care providers' perspectives. While interviews were effective and insightful, direct observations of how interactions occur in specific contexts would provide additional richness to the analysis. Finally, findings represent the experiences of English-speaking families within a single academic ICU in Canada and may not be transferable to non-English speaking families and/or other ICUs.

\section{Conclusions}

The four dimensions of therapeutic alliance prove analytically useful to highlight current strength in ICU provider-family relationships. We identified several opportunities to improve these relationships in the areas of family integration and empowerment. In our center, we have implemented a comprehensive informational website for families, an initiative that aligns with the SCCM's family-centered care guideline for family education [1]. Our website aims to increase access to and understanding of ICU personnel and processes, and support families' integration into care. We have sought to expand on the guideline's recommendations on family-centered communication training for ICU clinicians by implementing role-playing exercises for critical care trainees to highlight the importance of informal family 
interactions that target family empowerment. Future efforts to build therapeutic alliance should also consider educational activities that enable physicians and other providers to reflect on the norms and practices that produce inequality across the provider-family dyad [52]. Further research is necessary to understand the best ways to integrate families into rounds, how to build on the complementary roles and practices of physicians and nurses, and how informal interactions shape and constrain family-provider relationships. Multiple interventions are likely needed to continually foster positive relationships, mitigate identified barriers and transform the ICU into a more interprofessional and family-centered therapeutic environment to enhance patient- and family outcomes.

\section{Additional file}

Additional file $\mathbf{1}$ Interview Guide. This file contains the semi-structured interview guide that was used to guide discussions with research participants. (DOCX 17 kb)

\section{Abbreviation}

ICU: Intensive care unit

\section{Acknowledgements}

We would like to thank the family members who talked to us in the midst of their loved ones' critical illness.

\section{Availability of data materials}

The datasets used and analysed during the current study are available from the corresponding author on reasonable request. As the hospital's Research Ethics Board approved, all paper documents of interview transcripts related to this study is kept in the corresponding author's secure research office. All electronic interview transcripts related to this study is stored and coded in NVivo in a password-protected file on a secure hospital server.

\section{Funding}

The study was supported by The Innovation Fund of the Alternative Funding Plan for the Academic Health Sciences Centres of Ontario. The funding body had no role in the design of the study and the collection, analysis, and interpretation of data and in writing the manuscript.

\section{Authors' contributions}

Study design and concept: AA, DP, GW, SPD, PT, JD, LGC; data collection: CK; data analysis and interpretations: CK, AA, DP, LGC; writing and review: CK, AA, DP, GW, SPD, PT, JD, LGC; acquisition of funding: AA, DP, GW, SPD, PT, JD, LGC; final approval: CK, AA, DP, GW, SPD, PT, JD, LGC; accountable for all work: CK, AA, DP, GW, SPD, PT, JD, LGC. All authors read and approved the final manuscript.

\section{Ethics approval and consent to participate}

The Sunnybrook Health Sciences Centre's Research Ethics Board approved the study (325-2014) and all interviewees provided written informed consent.

\section{Consent for publication}

Not applicable.

\section{Competing interests}

The authors declare that they have no competing interests. The views expressed in this article do not communicate an official position of the funding source. There are no financial relationships with any organizations that might have an interest in the submitted work and no other relationships or activities that could appear to have influenced this work.

\section{Publisher's Note}

Springer Nature remains neutral with regard to jurisdictional claims in published maps and institutional affiliations.

\section{Author details}

${ }^{1}$ Trauma, Emergency and Critical Care Research, Evaluative Clinical Sciences, Sunnybrook Research Institute, Toronto, Canada. ${ }^{2}$ Interdepartmental Division of Critical Care, University of Toronto, Toronto, Canada. ${ }^{3}$ Sunnybrook Health Sciences Centre, Toronto, Canada. ${ }^{4}$ Palliative Medicine, University of Toronto, Toronto, Canada. ${ }^{5}$ Patient/Client and Family Education, Centre for Mental Health and Addiction, 33 Russell Street, Toronto, Ontario M5S 3M1, Canada.

Received: 29 November 2017 Accepted: 28 June 2018

Published online: 09 July 2018

\section{References}

1. Davidson JE, Aslakson RA, Long AC, Puntillo KA, Kross EK, Hart J, Cox CE, Wunsch H, Wickline MA, Nunnally ME, Netzer G, Kentish-Barnes N, Sprung CL, Hartog CS, Coombs M, Gerritsen RT, Hopkins RO, Franck LS, Skrobik Y, Kon AA, Scruth EA, Harvey MA, Lewis-Newby M, White DB, Swoboda SM, Cooke CR, Levy MM, Azoulay E, Curtis JR. Guidelines for family-centered Care in the Neonatal, pediatric, and adult ICU. Crit Care Med. 2017:45(1):103-28.

2. Studdert DM, Mello MM, Burns JP, Puopolo AL, Galper BZ, Truog RD, Brennan TA. Conflict in the care of patients with prolonged stay in the ICU: types, sources, and predictors. Intensive Care Med. 2003;29:1489-97.

3. Azoulay E, Timsit JF, Sprung CL, Soares M, Rusinova K, Lafabrie A, Abizanda R, Svantesson M, Rubulotta F, Ricou B, Benoit D, Heyland D, Joynt G, Francais A, Azeivedo-Maia P, Owczuk R, Benbenishty J, de Vita M, Valentin A, Ksomos A, Cohen S, Kompan L, Ho K, Abroug F, Kaarlola A, Gerlach H, Kyprianou T, Michalsen A, Chevret S, Schlemmer B. Prevalence and factors of intensive care unit conflicts: the conflicus study. Am J Respir Crit Care Med. 2009;180(9):853-60.

4. Meth ND, Lawless B, Hawryluck L. Conflicts in the ICU: perpectives of administrators and clinicians. Intensive Care Med. 2009;35:3068-2077.

5. Fassier T, Azoulay E. Conflicts and communication gaps in the intensive care unit. Curr Opin Crit Care. 2010;16(6):654-65.

6. Long AC, Curtis JR. The epidemic of physician-family conflict in the ICU and what we should do about it. Crit Care Med. 2014;42(2):461-2.

7. Schuster RA, Hong SY, Arnold RM, White DB. Investigating conflict in ICUs is the clinicians' perspective enough? Crit Care Med. 2014;42(2):328-35.

8. Abbott KH, Sago JG, Breen CM, Abernethy AP, Tulsky JA. Families looking back: one year after discussion of withdrawal or withholding of lifesustaining support. Crit Care Med. 2001;29(1):197-201.

9. Wall RJ, Curtis JR, Cooke CR, Engelberg RA. Family satisfaction in the ICU. Chest. 2007;132:1425-33.

10. Heyland DK, Rocker GM, Dodek PM, Kutsogiannis DJ, Konopad E, Cook DJ, Peters S, Tranmer JE, O'Callaghan CJ. Family satisfaction with care in the intensive care unit: results of a multiple center study. Crit Care Med. 2002; 30(7):1413-8.

11. Kentish-Barnes N, Lemieale V, Chaize M, Pochard F, Azoulay E. Assessing burden in families of critical care patients. Crit Care Med. 2009;37(10):S448-56.

12. Embriaco N, Hraiech S, Azoulay E, Baumstarck-Barrau K, Forel JM, KentishBarnes N, Pochard F, Loundou A, Roch A, Papazian L. Symptoms of depression in ICU physicians. Ann Intensive Care. 2012;2:34

13. Embriaco N, Papazian L, Kentish-Barnes N, Pochard F, Azoulay E. Burnout syndrome among critical care healthcare workers. Curr Opin Crit Care. 2007: 13:482-8.

14. Curtis JR, Back AL, Ford DW, Downey L, Shannon SE, Doorenbos AZ, Kross EK, Reinke LF, Feemster LC, Edlund B, Arnold RW, O'Connor K, Engelberg RA. Effect of communication skills training for residents and nurse practitioners on quality of communication with patients with serious illness: a randomized trial. JAMA. 2013;310(21):2271-81.

15. Curtis JR, Treece PD, Nielsen EL, Gold J, Ciechanowski PS, Shannon SE, Khnadelwal N, Young JP, Engelberg RA. Randomized trial of communication facilitators to reduce family distress and intensity of end-of-life care. Am J Respir Crit Care Med. 2016;193(2):154-62.

16. Lautrette A, Darmon M, Megarbane B, Joly LM, Chevret S, Andrie C, Barnoud D, Bleichner G, Bruel C, Choukroun G, Curtis JR, Fieux F, Galliot R, GarrousteOrgeas M, Georges H, Goldgran-Toledano D, Jourdain M, Loubert G, Reignier J, Saidi F, Souweine B, Vincent F, Kentish-Barnes N, Pochard F, 
Schlemmer B, Azoulay E. A communication strategy and brochure for relatives of patients dying in the ICU. N Engl J Med. 2007:356(5):469-78.

17. Schneiderman LJ, Gilmer T, Teetzel HD, Dugan DO, Blustein J, Cranford R, Briggs KB, Komatsu Gl, Goodman-Crews P, Cohn F, Young EDW. Effect of ethics consultations on nonbeneficial life-sustaining treatments in the intensive care setting: a randomized controlled trial. JAMA. 2003; 290(9):1166-72

18. Principal Investigators SUPPORT. A controlled trial to improve care for seriously ill hospitalized patients. The study to understand prognoses and preferences for outcomes and risks of treatments (SUPPORT). JAMA. 1995; 274(20):1591-8

19. Azoulay E, Chaize M, Kentish-Barnes N. Involvement of ICU families in decisions: fine-tuning the partnership. Ann Intensive Care. 2014;4:37.

20. Azoulay E, Sprung CL. Family-physician interactions in the intensive care unit. Crit Care Med. 2004:32(11):2323-8.

21. Nelson JE, Puntillo KA, Pronovost PJ, Walker AS, McAdam JL, llaoa D, Penrod J. In their own words: patients and families define high-quality palliative care in the intensive care unit. Crit Care Med. 2010;38(3):808-18.

22. Reeves S, McMillan SE, Kachan N, Paradis E, Leslie M, Kitto S. Interprofessional collaboration and family member involvement in intensive care units: emerging themes from a multi-sited ethnography. J Interprof Care. 2015;29(3):230-7.

23. Schaefer KG, Block SD. Physician communication with families in the ICU: evidence-based strategies for improvement. Curr Opin Crit Care. 2009;15(6):569-77.

24. Azoulay E, Pochard F, Chevret S, Adrie C, Annane D, Bleichner G, Bornstain C, Bouffard Y, Cohen Y, Feissel M, Goldgran-Toledano D, Guitton C, Hayon J, Iglesias E, Joly LM, Jourdain M, Laplace C, Lebert C, Pingat J, Poisson C, Renault A, Sanchez O, Selcer D, Timsit JF, Le Gall JR, Schlemmer B. Half the family members of intensive care unit patients do not want to share in the decision-making process: a study in 78 French intensive care units. Crit Care Med. 2004;32(9):1832-8.

25. Kim SC, Boren D, Solem SL. The Kim alliance scale: development and preliminary testing. Clin Nurs Res. 2001;10(3):314-31.

26. Kim SC, Kim S, Boren D. The quality of therapeutic alliance between patient and ProviderPpredicts general satisfaction. Mil Med. 2008;173(1):85-90

27. Kim SC, Yates AD, Graham P, Brown CE. Family-provider alliance program in intensive care units. Clin Nurs Res. 2011;20(3):245-62.

28. Martin DJ, Garske JP, Davis MK. Relation of the therapeutic alliance with outcome and other variables: a meta-analytic review. J Consult Clin Psychol. 2000;68(3):438-50

29. Mack JW, Block SD, Nilsson M, Wright A, Trice E, Firedlander R, Paulk E, Prigerson HG. Measuring therapeutic alliance between oncologists and patients with advanced cancer: the human connection scale. Cancer. 2009;115:3302-11.

30. Elvins $\mathrm{R}$, Green J. The conceptualization and measurement of therapeutic alliance: an empirical review. Clin Psychol Review. 2008;28:1167-87.

31. Huff NG, Nadig N, Ford DW, Cox CE. Therapeutic alliance between the caregivers of critical illness survivors and intensive care unit clinicians. Ann Am Thorac Soc. 2015;12(11):1646-53.

32. Lincoln YS, Guba EG. 1994 paradigmatic controversies, contradictions, and emerging confluences. In: Denzin NK, Lincoln YS, editors. Handbook of qualitative research. Thousand Oaks: Sage; 2015. p. 105-17.

33. Sobo EJ. Culture and meaning in health services research: a practical field guide. Walnut Creek: Left Coast Press; 2009.

34. Bernard HR, Ryan GW. Analyzing qualitative data : systematic approaches. Los Angeles: Sage; 2010.

35. Curtis JR, Ciechanowski PS, Downey L, Gold J, Nielsen EL, Shannon SE, Treece PD, Young JP, Engelberg RA. Development and evaluation of an interprofessional communication intervention to improve family outcomes in the ICU. Contemp Clin Trials. 2012;33(6):1245-54.

36. Leslie M, Paradis E, Gropper MA, Milic MM, Kitto S, Reeves S, Pronovost P. A typology of ICU patients and families from the clinician perspective: toward improving communication. Health Commun. 2016;

37. Slatore CG, Hansen L, Ganzini L, Press N, Osborne ML, Chesnutt MS, Mularski RA. Communication by nurses in the intensive care unit: qualitative analysis of domains of patient-centered care. Am J Crit Care. 2012;21(6):410-8.

38. White DB, Cua SM, Walk R, Pollice L, Weissfeld L, Hong S, Landefeld CS, Arnold RM. Nurse-led intervention to improve surrogate decision making for patients with advanced critical illness. Am J Crit Care. 2012;21(6):396-409.
39. Coombs M, Ersser SJ. Medical hegemony in decision-making - a barrier to interdisciplinary working in intensive care? J of Adv Nurs. 2004:46(3):245-52.

40. Lingard L, Espin S, Evans C, Hawryluck L. The rules of the game: inteprofessional collaboration on the intensive care unit team. Crit Care. 2004;8(6):R403-8.

41. Thomas EJ, Sexton JB, Helmreich RL. Discrepant attitudes about teamwork among critical care nurses and physicians. Crit Care Med. 2003;31(3):956-9.

42. Paradis E, Leslie M, Puntillo K, Gropper MA, Aboumata HJ, Kitto S, Reeves S. Delivering interprofessional care in intensive care settings: results from a scoping review of ethnographic studies. Am J Crit Care. 2014;23(3):230-9.

43. Alexanian JA, Kitto S, Rak KJ, Reeves S. Beyond the team: understanding interprofessional work in two north American ICUs. Crit Care Med. 2015; https://doi.org/10.1097/CCCM.00000000000001136.

44. Allen D, Braithwaite J, Sandall J, Waring J. Towards a sociology of healthcare safety and quality. Sociol Health IIIn. 2016;38(2):181-97.

45. Nimmon L, Stenfors-Hayes T. The "handling" of power in the physicianpatient encounter: perceptions from experienced physicians. BMC Med Educ. 2016;16:114.

46. Jacobowski NL, Girard TD, Mulder JA, Ely EW. Communication in critical care: family rounds in the intensive care unit. Am J Crit Care. 2010;19(5): 421-30.

47. Paradis $\mathrm{E}$, Leslie $\mathrm{M}$, Gropper MA. Interprofessional rhetoric and operational realities: an ethnographic study of rounds in four intensive care units. Adv Health Sci Educ. 2016:21(4):735-48.

48. Bourdieu P. Language and symbolic power. Cambridge: Polity Press; 1991.

49. Soderstrom IM, Saveman BI, Benzein E. Interactions between family members and staff in intensive care units-an observation and interview study. Int J Nurs Stud. 2006:43(6):707-16.

50. Lilly CM, De Meo DL, Sonna LA, Haley KJ, Massaro AF, Wallace RF, Cody S. An intensive communication intervention for the critically ill. Am J Med. 2000;109:469-75.

51. Curtis RJ, Engelberg RA, Wenrich MD, Shannon SE, Treece PD, Rubenfeld GD. Missed opportunities during family conferences about end-of-life care in the intensive care unit. Am J Respir Crit Care Med. 2005;171:844-9.

52. Ng SL, Kinsella EA, Firesen F, Hodges B. Reclaiming a theoretical orientation to reflection in medical education research: a critical narrative review. Med Educ. 2015:49:461-75.

\section{Ready to submit your research? Choose BMC and benefit from:}

- fast, convenient online submission

- thorough peer review by experienced researchers in your field

- rapid publication on acceptance

- support for research data, including large and complex data types

- gold Open Access which fosters wider collaboration and increased citations

- maximum visibility for your research: over $100 \mathrm{M}$ website views per year

At BMC, research is always in progress.

Learn more biomedcentral.com/submissions 